\title{
Cryoablation of a Mahaim Epicardial Accessory Pathway Inside Coronary Sinus Using an 8-mm Catheter
}

\author{
Bruno Pereira Valdigem ${ }^{1, *}$, Nilton José Carneiro da Silva ${ }^{1}$, Rogerio Braga Andalaft ${ }^{1}$, Carla \\ Almeida', Nilson Araujo Junior ${ }^{2}$, Fernando Scazzuso ${ }^{3}$, Olga F. de Souza²
}

\section{ORCID IDs}

Valdigem BP (D) https://orcid.org/0000-0003-0676-2033

Siva NJC (D) https://orcid.org/0000-0002-4037-5240

Andalaft RB (D) https://orcid.org/0000-0002-5168-8496

\author{
Almeida C (D) https://orcid.org/0000-0002-3147-4175 \\ Araujo Junior N (D) https://orcid.org/0000-0002-9964-6332 \\ Scazzuso F (D) https://orcid.org/0000-0002-1623-0535 \\ Souza OF (D) https://orcid.org/0000-0003-2733-4644
}

\begin{abstract}
Cyoablation is a ablation technique underutilized except in parahissian pathways and atrial fibrillation ablation. Ablation inside venous coronary sinus remains a dreaded incursion, and cryoablation is rarely used. We present the case of a 43 YO female who had a recurrent wolff parkinson white syndrome due to an epicardial pathway inside the coronary sinus successfully treated with a large bore $(8 \mathrm{~mm})$ cryocatheter. We also review literature and describe the advantages and similar reports of use of cryo in low flow recesses inside the heart.
\end{abstract}

KEYWORDS: Tachycardia; Supraventricular; Catheter ablation; Arrhythmias; Cardiac.

\section{INTRODUCTION}

Radiofrequency ablation of accessory pathways was first described in the late 80s and grew into current practice in the early $90 \mathrm{~s}^{1}$. As technology evolved, better catheters were developed, which provided more control and accuracy. Recently, the quest for new ways to create myocardial lesion has yield results. Focal cryoablation was first described in Brazil in 2015. This technology creates myocardial lesion through lowering the catheter tip temperature close to $-80^{\circ} \mathrm{C}^{2}$. Cryoablation has some advantages over radiofrequency ablation, as the ability of cryomap (lower the temperature to $-30^{\circ} \mathrm{C}$ to achieve a reversible lesion, thus reassuring safety and efficacy before the definitive lesion is placed) ${ }^{3}$ and the lower probability of coronary vessel thrombosis when cryo is delivered in their vicinity ${ }^{4}$.

1. Rede D'or São Luiz - São Paulo (SP), Brazil.

2. Rede D'or São Luiz - Rio de Janeiro (RJ), Brazil.

3. Instituto Cardiovascular de Buenos Aires - Buenos Aires, Argentina.

*Corresponding author: valdigem@gmail.com

Received: Mar 2, 2021 | Accepted: Apr 26, 2021 


\section{CASE REPORT}

A 43-year-old female underwent catheter radiofrequency ablation of postero-septal right accessory pathway 13 months ago. She was referred to our hospital due to paroxysmal tachycardia after a failed ablation attempt. Electrocardiography (ECG) in sinus rhythm showed discrete preexcitation. The echocardiogram was normal (Fig. 1).

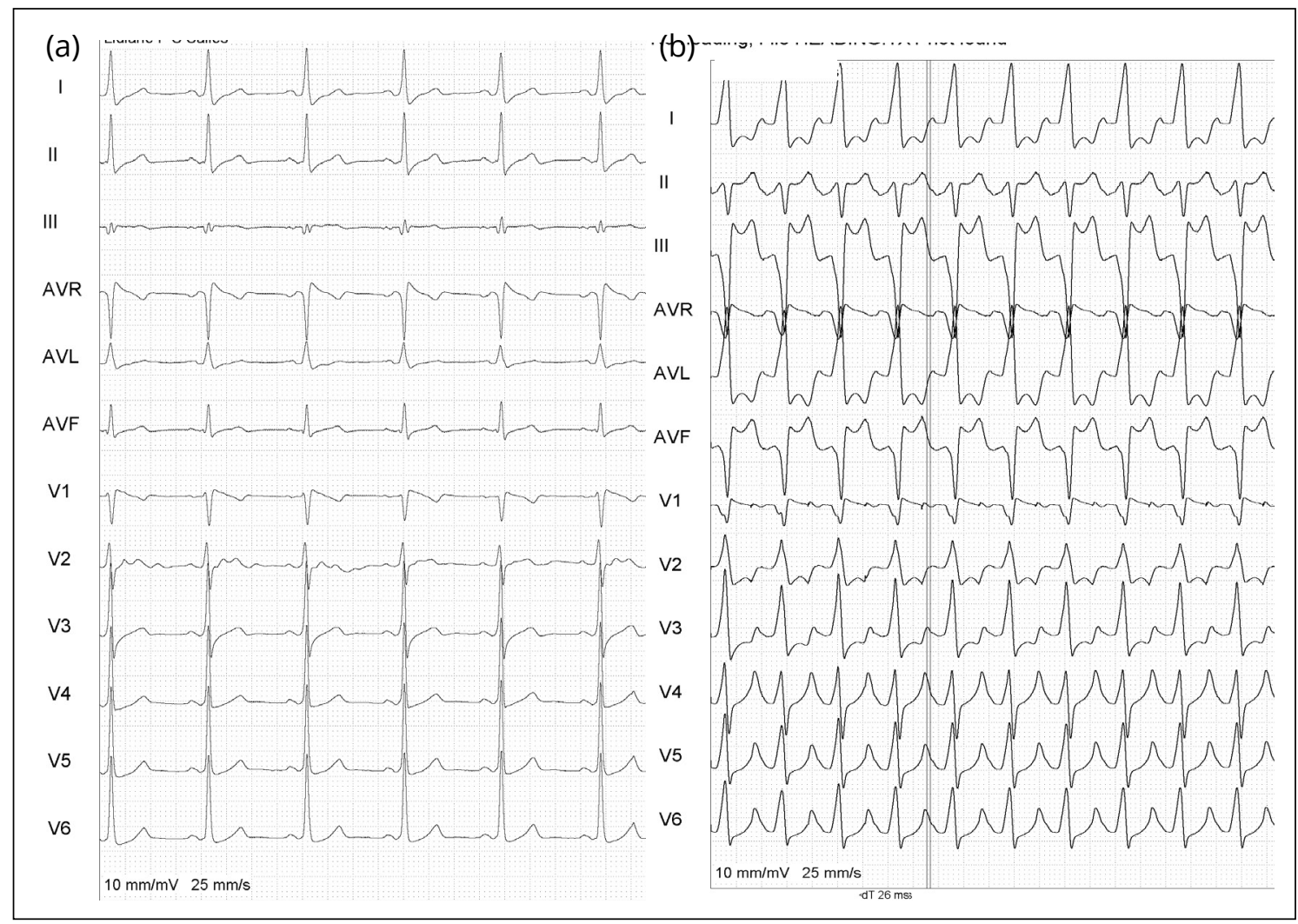

ECG: electrocardiography.

Figure 1. (a) Baseline ECG. (b) ECG during incremental atrial pace.

After informed consent, the patient underwent a second ablation procedure. Two quadripolar catheters and one decapolar were placed in the right atrium, right atrial septum and coronary sinus, through the right femoral vein. The accessory pathway had decremental atrioventricular (AV) properties without retrograde conduction. The 12-mg Adenosine bolus injection blocked both the AV node and the accessory pathway.

These findings suggested the presence of a Mahaim type accessory pathway. The anterograde refractory period of the accessory pathway was $270 \mathrm{~ms}$. We have found that the earliest ventricular electrogram to delta wave (26 ms) was located $1 \mathrm{~cm}$ inside the coronary sinus (Figs. 1-4). Epicardial pathways often do not show AV fusion due to the layers of myocardial tissue between the inside of coronary sinus and the epicardium. Also, previous ablations may have caused small areas of electrical low amplitude signals before the clear ventricular electrogram that might not be easily identifiable without high-density mapping catheters. Because of the necessity of producing effective lesions inside the coronary sinus and of minimizing the risk of perforation and collateral damage to the coronary arteries located nearby, we decided to use an 8-mm tip cryoablation catheter.

Ablation was performed with mild sedation, and we paced from the right atrial appendage to maximize the preexcitation pattern. One cryoablation application was performed for 4 minutes at $-80^{\circ} \mathrm{C}$. Pathway block occurred 12 seconds after the application started. The patient was observed for 40 minutes, and no pre-excitation was observed by pacing maneuvers or Adenosine infusion. The patient returned after 30 days with a 24-hour Holter recording without signs of pre-excitation. 
(a) No heading, File HEADING.TXT not found

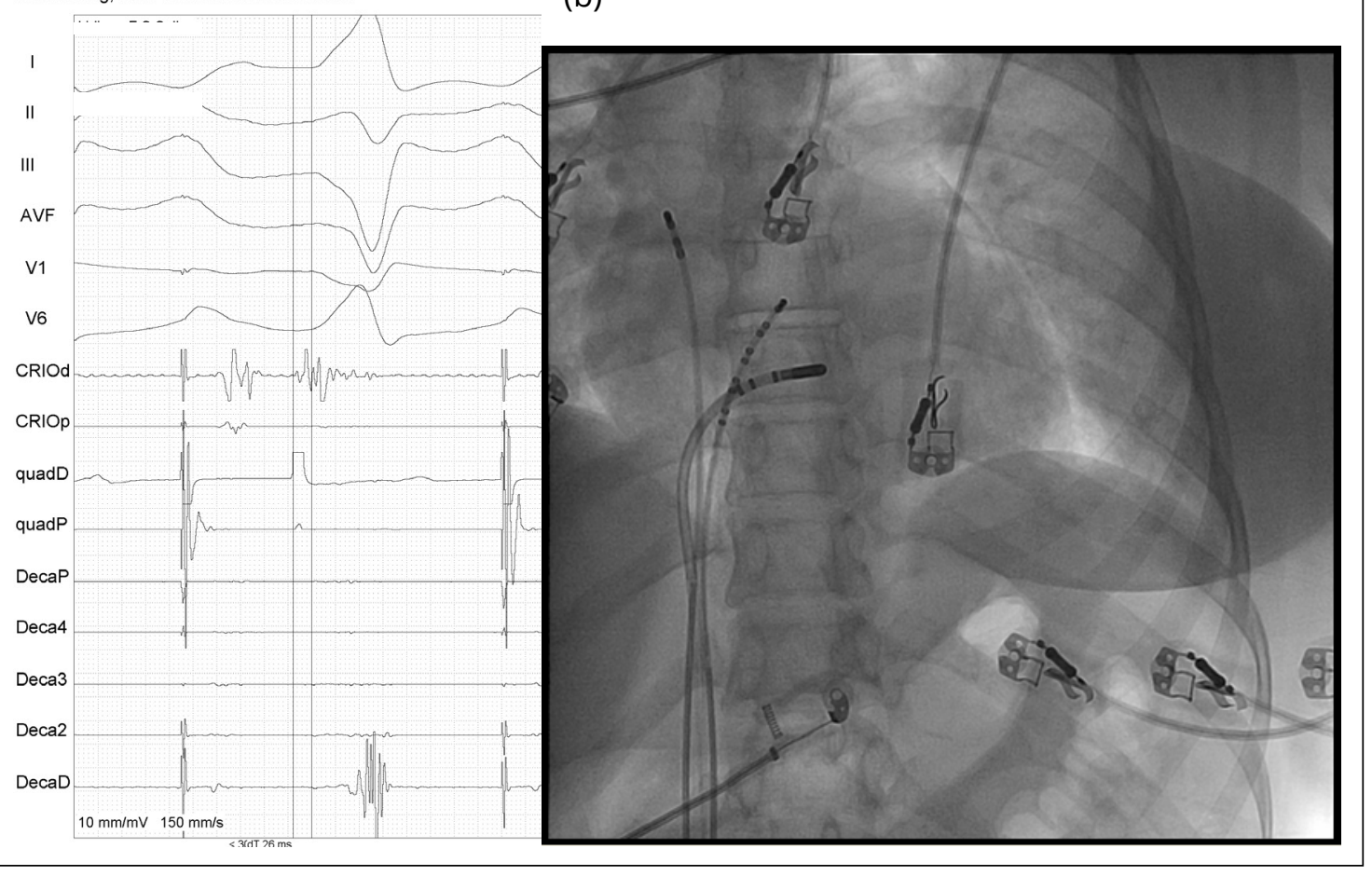

Figure 2. (a) Electrogram before ablation. (b) X-ray catheter positioning.

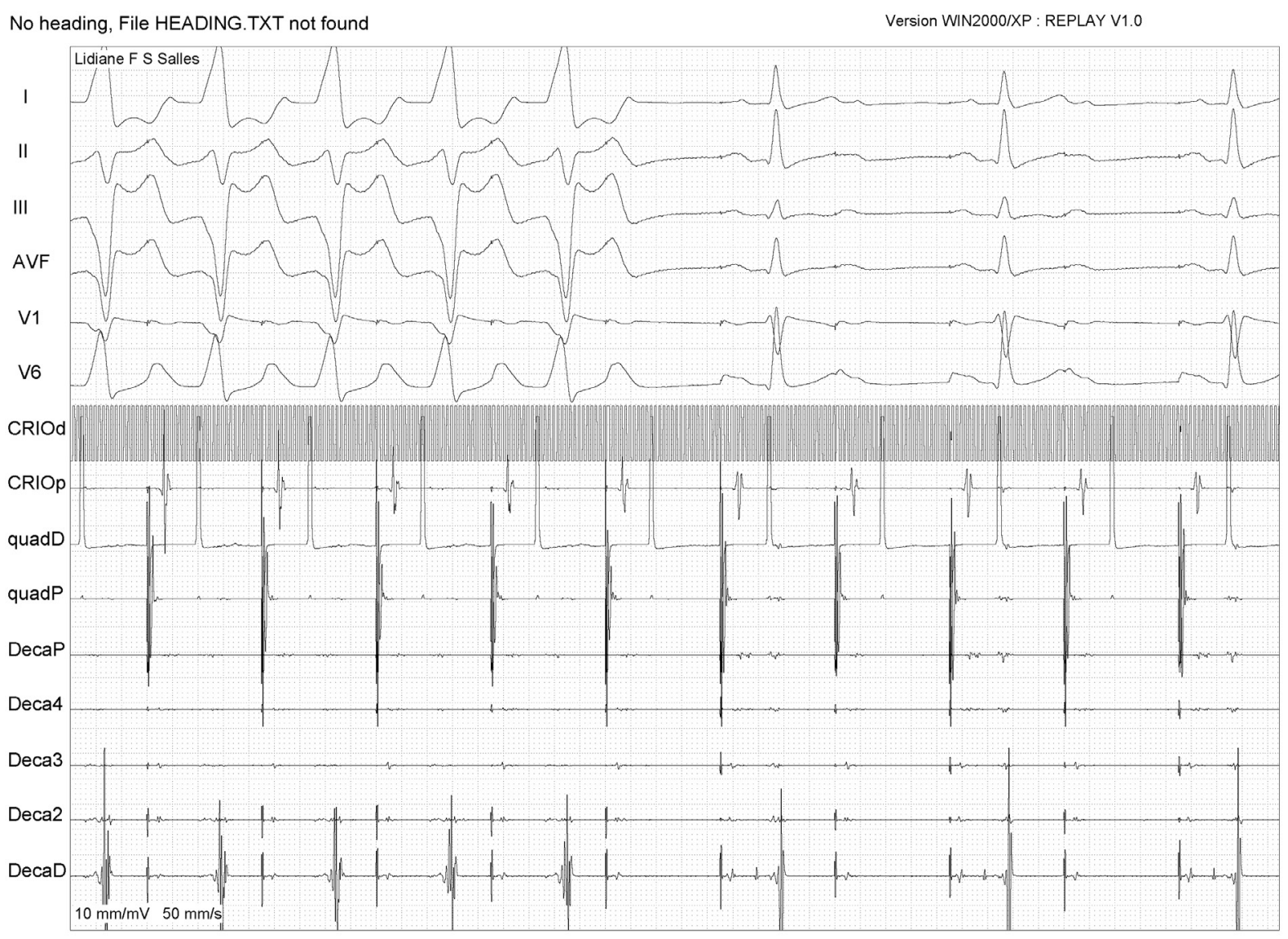

Figure 3. Pathway cryoablation during fast atrial pacing. 
ECG after ablation can be seen in Fig. 4.

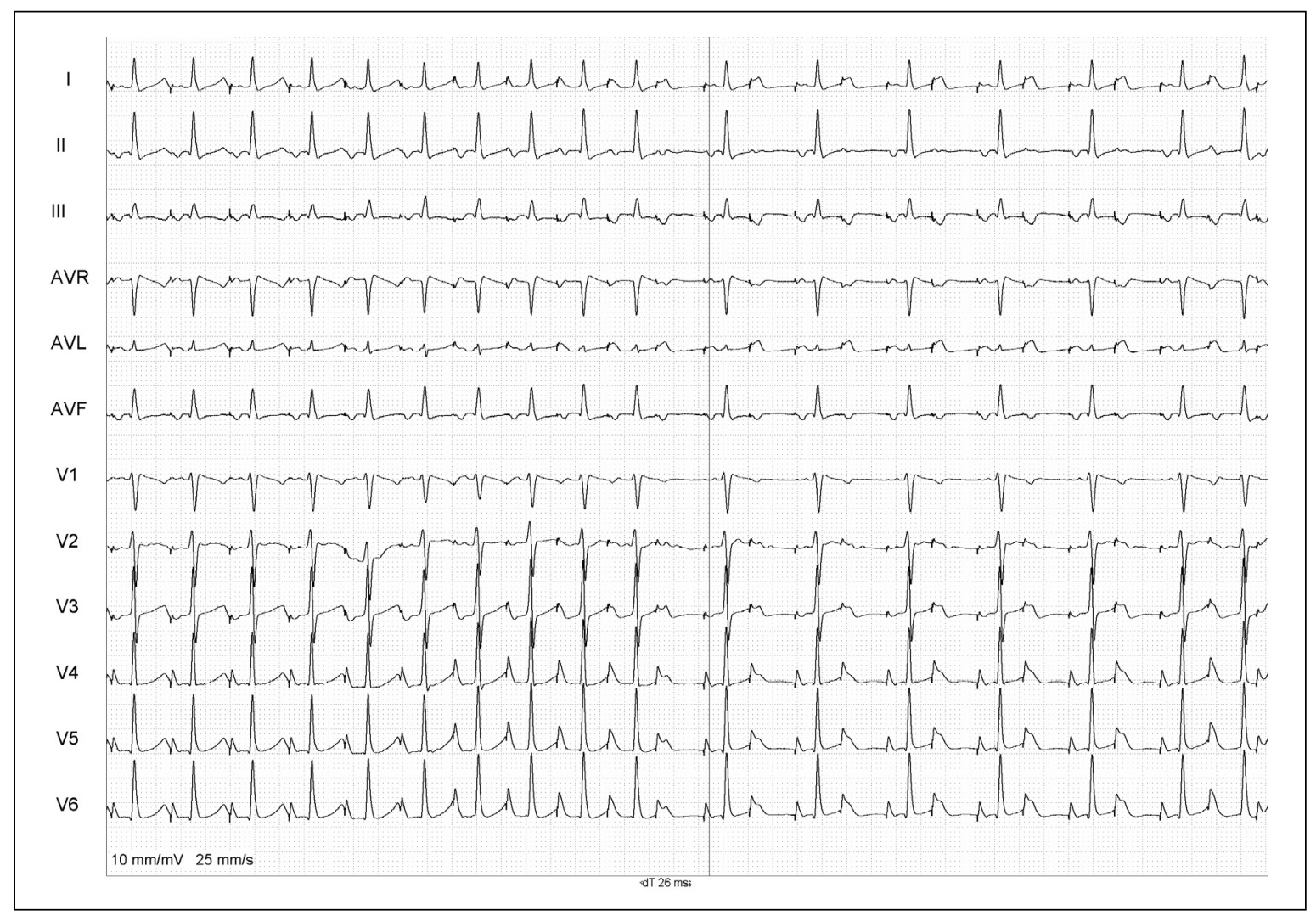

Figure 4. Electrocardiography 45 minutes after ablation, during atrial incremental pacing.

\section{DISCUSSION}

Therapeutic ablation by lowering tissue temperatures was first described by Hass and Taylor in $1947^{5}$. Since then, many technological advances were achieved, and nowadays we have both so-called focal ablation catheters, used mainly for accessory pathways and $\mathrm{AV}$ reentry ablations, and balloons, for pulmonary vein isolation in atrial fibrillation ablation procedures. The catheters for focal ablation come in three tip sizes: 4,6 and $8 \mathrm{~mm}$. If the operator uses 4 or 6-mm catheters, it is possible to perform cryomapping. When temperatures approach $-30^{\circ} \mathrm{C}$, they create a reversible lesion. The goal should be achieved before 60 seconds of mapping (or even better, before 20 seconds of mapping) to increase success rate. The lesion should not incur in atrioventricular block or sinus node disease during the cryomapping, in which case it should be discontinued.

Cryoablation is initiated when an adequate cryomapping is achieved or when the operator feels safe to initiate ablation. Temperature is lowered to $-80^{\circ} \mathrm{C}$ for 4 minutes, followed by another 4 minutes ${ }^{3}$. When deeper lesions are needed, $8-\mathrm{mm}$ catheters should be preferred. When compared to cooled tip radiofrequency catheters, the size of the ablated tissue can vary according to some factors. Crioablation $8-\mathrm{mm}$ catheters can achieve a more extensive lesion if the tip lays parallel to the endocardium (opposite to cooled tip catheters) ${ }^{6}$. Areas with slower blood flow favor cryoablation, as well as areas with expected or known high impedance. As there is no energy current to transverse the tissue, impedance is not a concern for focal cryoablation, but it could be an obstacle to radiofrequency delivery ${ }^{6}$.

Cryoablation near vessels was described by $\mathrm{Di}$ Biase et al., who reported a low risk of vessel thrombosis even with delivery close to coronary arteries ${ }^{4}$. Cryoablation inside coronary sinus has been described with smaller catheters ( 4 and $6 \mathrm{~mm})^{6-8}$. This case report offers an alternative approach to radiofrequency ablation inside coronary sinus in an antegrade decremental pathway. 


\section{CONCLUSION}

Cryoablation using $8-\mathrm{mm}$ catheters is feasible and seems for ablation inside the coronary sinus. Focal cryoablation should always be considered as an alternative to ablation inside small areas or those in which an irrigated might not reach an adequate position, as inside vessels, or might cause undesired damage (as in the vicinity of coronary arteries or AV node).

\section{FUNDING}

Not applicable.

\section{AUTHORS' CONTRIBUTION}

Conceptualization, Data curation, Formal analysis, Writing - first draft, Writing - review \& edition: Valdigem BP, Silva NJC, Andalaft RB, Almeida C, Araujo Junior N, Scazzuso F, Souza OF.

\section{DATA AVAILABILITY STATEMENT}

The datasets generated during and/or analyzed during the current study are available from the corresponding author on reasonable request.

\section{REFERENCES}

1. Soubera C, Cohen M, Christiana J. Radiofrequency catheter ablation: the first decade. Heart Dis. 1999;1(4):210-20.

2. Andalaft R, Valdigem B, Carneiro da Silva NJ, Makdisse MRP, Perin MA. Crioablação de via anômala anterosseptal Parahissiana: Uma nova esperança para pacientes com WPW e vias acessórias de alto risco. Revista DERC. 2015;21(4):106-9.

3. Chan NY. Catheter cryoablation for the treatment of accessory pathways. In: Chan NY, editor. The practice of catheter cryoablation for cardiac arrhythmias. Hoboken: John Wiley \& Sons; 2014. p. 36-46.

4. Di Biase L, Al-Ahamad A, Santangeli P, Hsia HH, Sanchez J, Bai R, et al. Safety and outcomes of cryoablation for ventricular tachyarrhythmias: results from a multicenter experience. Heart Rhythm. 2011;8(7):968-74. https://doi.org/10.1016/j. hrthm.2011.02.038

5. Hass GM, Taylor CB. A quantitative hypothermal method for production of local injury to tissue. Federation Proc. 1947;6(1):393.

6. Parvez B, Pathak V, Schubert CM, Wood M. Comparison of lesion sizes produced by cryoablation and open irrigation radiofrequency ablation catheters. J Cardiovasc Electrophysiol. 2008;19(5):528-34. https://doi.org/10.1111/j.1540-8167.2007.01072.x

7. Collins KK, Rhee EK, Kirsh JA, Cannon BC, Fish FA, Dubin AM, et al. Cryoablation of accessory pathway in the coronary sinus in young patients: a multicenter study from the pediatric and congenital Electrophysiology Society Working group on Cryoablation. J Cardiovasc Electrophysiol. 2007;18(6):592-7. https://doi.org/10.1111/j.1540-8167.2007.00831.x

8. De Sisti A, Tonet J, Marrakchi S, Raguin D, Frank R. Effective cryoablation of a lateral accessory pathway within the distal coronary sinus J Interv Card Electrophysiol. 2008;22(3):189-93. https://doi.org/10.1007/s10840-008-9273-7 